Dossiê: Espiritualidades, Filosofias e Religiões do Oriente - Artigo Original (a) (1)

\title{
O Budismo de imigrantes japoneses no âmbito do Budismo brasileiro
}

\author{
Buddhism of Japanese Immigrants within the framework \\ of Brazilian Buddhism
}

Frank Usarski

\begin{abstract}
Resumo
O artigo reflete sobre o Budismo de imigrantes japoneses que é no Brasil o segmento histórico e numericamente mais importante do chamado "Budismo étnico". O último representa, ao lado do Budismo de conversão, uma das duas principais subcategorias analíticas do universo budista do País. O texto começa com uma reconstrução da trajetória desta corrente religiosa em relação a outras tendências observáveis no campo budista em geral. Por razões analíticas, a história da Budismo de imigração japonesa é subdividida em quatro fases. A segunda parte do artigo submete os dados anteriormente apresentados à uma avaliação sociológica. Tal interpretação apropria-se, sobretudo, das estatísticas referente ao Budismo fornecidas pelo IBGE por meio dos censos nacionais desde 1950. Os dados indicam um declínio gradativo do Budismo de imigração no decorrer das últimas décadas que culminou em uma crise generalizada do segmento do Budismo em questão. Na busca para os possíveis fatores responsáveis por desenvolvimento negativo, o artigo contempla aspectos como a falta de recursos e falhas logísticas por parte de instituições budistas ou a dificuldade das famílias de descendência japonesa em transmitir sua herança religioso-cultural para seus filhos.
\end{abstract}

Palavras-chave: Budismo de imigrantes japoneses; Budismo brasileiro; crise religiosa

\begin{abstract}
The article reflects upon Buddhism of Japanese immigrants, which is the historically and numerically most important sub-segment of the so-called "ethnic Buddhism" in Brazil. The latter represents - in distinction from the "Buddhism of converts" - one of the two principles analytical subcategories of Buddhist universe of the country. The text starts with a reconstruction of the trajectory of the religious sub-segment in question by relating it to other observable tendencies in Brazil's Buddhist field in general. For analytical reasons, the history of Buddhism of Japanese immigrants is subdivided into four phases. In the second part of the article the aforementioned data are interpreted from a sociological point of view. This interpretation refers mainly to the statistics of the National Census from 1950 onwards conducted by the Brazilian Institute of Geography and Statistics (IBGE). The data indicate a gradual decline of Japanese Immigrant Buddhism during the last decades that has cumulated into general crises of the Buddhist segment in question. As for factors possibly responsible for this negative development, the article discusses aspects such as logistical failures on the side of the Buddhist institutions or the difficulties of the families of Japanese descendants in handing down their cultural and religious heritage to their children.
\end{abstract}

Keywords: Buddhism of Japanese immigrants; Brazilian Buddhism; religious crises

Artigo recebido em 21 de abril de 2016 e aprovado em 22 de setembro de 2016.

* Livre Docente na área de Ciências da Religião pela PUC-SP, Doutor com tese sobre os mecanismos e motivos da estigmatização pública de Novos Movimentos Religiosos na Alemanha Ocidental (1987) e pós-doutorado (1992-93) na área de Ciência da Religião pela Universidade de Hannover (Alemanha) sobre o papel das religiões nas Exposições Mundiais entre 1851 e 1900. País de origem: Alemanha.E-mail: usarski@pucsp.br.

Horizonte, Belo Horizonte, v. 14, n. 43, p. 717-739, jul./set. 2016 - ISSN 2175-5841 


\section{Introdução}

Aproximando-se o objeto deste artigo a partir da diferenciação analítica “clássica" entre o "Budismo étnico" e o "Budismo de conversão", como duas vertentes do Budismo ocidental, percebe-se uma predominância relativamente incomum dos imigrantes asiáticos no âmbito do Budismo brasileiro. Isso vale particularmente em termos históricos, mas também no sentido do impacto do Budismo étnico sobre a evolução do campo budista brasileiro, a partir da década de 1950 para frente. Enquanto o Budismo, por exemplo, na Inglaterra ou na Alemanha, foi "importado" devido a um interesse por esta religião por parte de círculos ocidentais, o "Budismo de conversão" no Brasil é um fenômeno mais recente, antecedido por movimentos imigratórios, sobretudo de japoneses, responsáveis pela presença notável do Budismo asiático em nosso país.

\section{Esboço histórico do Budismo brasileiro}

A grosso modo, a história do Budismo no Brasil pode ser subdividida em quarto períodos. A recuperação destas fases não deve ser confundida com a tentativa de descrever passos evolutivos nitidamente diferenciados. Em vez disso, busca-se indícios para características predominantes em determinados momentos, contextualizados em um fluxo cronológico contínuo e altamente complexo.

\subsection{A primeira fase}

A primeira fase abrange as décadas do século XIX e a primeira metade do século XX. Neste período o Budismo era quase completamente restrito aos imigrantes da Ásia e suas práticas domésticas e seus esforços de manter sua herança cultural, trazida para um país geralmente considerado um país anfitrião transitório. Conforme relatos da época, isso já vale - em uma escala menor - para a numericamente modesta imigração chinesa do século XIX. (BUSSCHE 1999; ELIAS 1970; LEITE, 1999; LESSER 1999a; YANG, 1995). 
Mais relevante para a história do Budismo brasileiro, do que os tímidos movimentos imigratórios de chineses no decorrer do século XIX, foi a chegada de 186.272 imigrantes japoneses oficialmente registrados entre 1908 e o início da Segunda Guerra Mundial (IZUMI, 2012, p.30). Nos meios dos imigrantes japoneses da época, a prática budista predominante era associada ao Budismo Shin, caracterizado pela devoção coletiva ao Buda Amida em desfavor de aspectos meditativos típicos para o Budismo Zen ou de exigências intelectuais típicas de um Budismo "erudito". No Brasil, o caráter coletivo do Budismo Shin foi preservado pelo fato de que durante as primeiras décadas da imigração japonesa foi impedida a entrada individual ao país. Em vez disso, apenas famílias compostas por no mínimo três membros adultos capazes de trabalhar tinham permissão para entrar no país. Conforme as estatísticas, 98,8\% dos imigrantes antes da Segunda Guerra Mundial provinham das zonas agrícolas onde o Amida Budismo era tradicionalmente dominante. Dos 188.940 japoneses que vieram para o Brasil entre 1908 e 1941, estima-se que 94,5\%, ou seja, 178.128 indivíduos chegaram junto com parentes. (MAEYAMA,1973, p.244)

Pelo fato de que uma boa parte dos imigrantes não tinha a intenção de permanecer no Brasil, mas de lucrar na medida do possível a curto prazo e retornar para Japão, não se via a necessidade de uma adaptação linguística, cultural e religiosa no país anfitrião. Também não foram tomadas providências sistemáticas em prol de institucionalização do Budismo. Devido à ausência de templos e por causa da falta de sacerdotes, grupos de parentes reuniam-se em momentos oportunos junto com seus vizinhos para realizar - de forma improvisada cerimônias religiosas. Isso aconteceu, por exemplo, em situações em que um integrante da colônia japonesa falecia longe da sua terra nativa e sem a possibilidade de desfrutar de um rito fúnebre, realizado conforme a tradição budista por um bonzo legitimado local.

Afirma Handa: 
Por absoluta escassez de bonzos, estes eram quase sempre substituídos por leigos que soubessem rezas budistas, não importando de que seita fossem. Quando não havia nem mesmo esses "bonzos" improvisados, cada qual rezava à sua moda, enquanto queimava incenso funerário à cabeceira do morto [...]. Em todas essas ocasiões, os imigrantes bem que gostariam que as diferenças entre as seitas fossem convenientemente observadas; mas, como antes da guerra não existiam nem templos budistas nem bonzos em número suficiente, tudo acabava sendo simplificado e ninguém, a não ser alguns, reclamava dessa indistinção inevitável de seitas (HANDA, 1987, pp.483-484).

Embora caraterísticas como práticas informais e a autonomia involuntária de leigos tenha sido a regra no período em questão (HANDA, 1987, p.238, p.359, p.483, p.725-726), não se deve esquecer que havia esforços pontuais em prol de um suporte institucional à vida espiritual em algumas das comunidades japonesas. A atividade mais notável está associada ao Reverendo Tomojiro Ibaragi, da linha budista Honmon Butsuryū-shū (NAKAMAKI, 2003, pp.43-167). O religioso tinha feito parte da primeira leva dos imigrantes e fundou em 1936, na cidade paulista de Guaiçara, o templo Taissenji, que apesar de ter sido transferido para a cidade de Lins, em 1951, é hoje considerado a primeira instituição oficial budista do País. Logo depois foi inaugurada, na cidade de Cafelândia, a primeira entidade do Budismo Shin. (GONÇALVES, 2004a). Paralelamente, o Reverendo Masumo Ikoma tomava providências religiosas na cidade de Iguape em nome da sua escola budista Honpa Honganji. Na mesma época, o Reverendo Shinba introduziu o Budismo da linha Shingon ao Brasil (SHOJI, 2006, p.43). Dois outros templos da escola Honmon Butsuryū-shū ainda foram construídos antes da Segunda Guerra Mundial, a saber: o Nissenji, em Presidente Prudente (1940), e o Ryushoji, em Moji das Cruzes (1941). (COMO, 2001).

Além dos poucos templos tradicionalmente japoneses deve-se mencionar um evento de natureza diferente, isto é, a fundação da Sociedade Budista do Brasil, em 1923 no Rio de Janeiro, pelo teósofo Lourenço Borges. Uma vez que se tratou da primeira associação intencionalmente designada para budistas ocidentais, sua abertura antecipou algumas tendências características para a fase posterior. Neste sentido, é sintomático que a Sociedade Budista do Brasil na sua forma original foi 
fechada apenas alguns meses após sua inauguração, mas reaberta em 1967, como uma instituição dedicada ao Budismo Teravada.

\subsection{A segunda fase}

A segunda fase do Budismo brasileiro coincide com o período pós-guerra. Para a grande maioria dos japoneses no Brasil, o sonho de enriquecer e retornar ao Japão não se realizou. Em vez disso, os respectivos imigrantes tomaram a decisão de permanecer no país anfitrião, apesar da política nacionalista repressiva, a partir de 1938, e hostilidades cotidianas nos anos da Segunda Guerra Mundial. Fatores como a derrota do Japão e as novas oportunidades econômicas depois da Guerra reconfirmaram a intenção de muitos de se estabelecerem para sempre no Brasil. A intenção de não voltar para o Japão encerrou a “imigração experimental”. O associado processo de aculturação refletia-se nos diversos segmentos de vida, inclusive na esfera da religião.

Quanto ao Budismo vale a pena lembrar que, no geral, no Japão, o Xintoísmo, o Budismo e, na maioria dos casos, as mais recentemente fundadas novas religiões coexistem harmoniosamente em termos institucionais. Ao mesmo tempo, devido às suas características especificas e lógicas particulares, as correntes cumprem funções diferentes, isto é, complementam-se em termos de apoio e conforto diante de problemas experimentados em diferentes níveis da existência. Neste sentido é comum que o mesmo indivíduo se identifique como "xintoísta" $\boldsymbol{e}$, como "budista", às vezes, também como aderente de um movimento como Seicho-no-Iê. Segundo Maeyama, do ponto de vista histórico, o Confucionismo e o associado culto ao Imperador eram mais associados ao ethos nacional em prol da coesão coletiva no nível "macro”. O Budismo era em primeiro lugar relacionado ao "lar" e ao parentesco, enquanto a maioria das novas religiões japonesas direcionava-se ao indivíduo. (MAEYAMA, 1983, p.205). 
A derrota do Japão e a posterior desistência pública do Imperador do seu tradicional status como figura divina tiveram um impacto profundo sobre a tradicional relação complementar entre as religiões. Privado da sua base legitimadora, o culto ao Imperador perdeu sua conotação imediatamente religiosa o que, no caso da colônia japonesa no Brasil, coincidiu com o desafio ambíguo de preservar a cultura do país de origem e ao mesmo tempo de se manter aberto para os desafios do abrasileiramento.

Pesquisas de campo indicam que no início dos anos 1950 o Budismo, devido à sua competência em questões sobre a morte e a vida além-túmulo, apresentou-se como um ambiente espiritual privilegiado em termos da manutenção da integridade étnica. Segundo Mita, na época em questão, na colônia de Bastos (SP) bem como em outras comunidades locais

muitos japoneses passaram a praticar o Budismo. [...] Antes da guerra os japoneses, em geral, não cuidavam bem dos túmulos de seus mortos, pois pretendiam regressar logo para o Japão. Porém, pode-se perceber, aqui, que os japoneses que perderam o "culto ao Imperador" e precisavam decidir-se pela permanência no Brasil, tentaram obter a estabilidade psicológica através do "culto ao ancestral" em forma budista. (MITA, 1999, p.177, p.179, p.181).

Simultaneamente, foi fundada uma série de entidades budistas associadas à comunidade japonesa. A escola Honmon-Busutryu-shu, que já possuiu três templos em solo brasileiro, expandiu sua rede de instituições para Taubaté (1949), Londrina (1950), e Itaguaí (1950). Em 1962, inaugurou sua sede na cidade de São Paulo. (COMO, 2001). Na primeira parte dos anos 50 a escola Tendai e o ramo Ōtani da escola Jōdo Shinshū abriram seus primeiros templos. O ramo Honpa da escola Jōdo Shinshū estabeleceu sua sede nacional na cidade de São Paulo. Outras linhas budistas, como a do Soto-Zen e do Nichiren-shu, anunciaram o início oficial das suas missões no Brasil. Em 1958 foi fundada a já mencionada organização de cúpula, Federação das Seitas Budistas no Brasil. (SASAKI, 1995). Estimulado pela internacionalização da sua (ainda dependente) organização leiga Soka Gakkai e a 
primeira visita do seu presidente, Ikeda Daisaku, ao Brasil, Nichiren Shōshū começou a se articular publicamente nos anos de 1960.

Todas estas instituições desempenharam um papel importante não apenas para os nipo-brasileiros, que deram continuidade a suas práticas budistas, mas também para os budistas nativos que entraram no país devido a um fluxo imigratório do pós-guerra, que na década de 1950 trouxe mais que 34.000 "novos" japoneses para o Brasil (BRASIL, 2013).

Para evitar uma associação precoce a respeito da relação entre os números absolutos, vinculados às diferentes ondas da imigração japonesa, e a evolução do Budismo brasileiro, é importante ressaltar que a afinidade de integrantes da colônia japonesa pelo Budismo era correlacionada a determinados fatores sociodemográficos. Conforme o censo da comunidade japonesa em 1958, a tendência de manter a religiosidade tradicional era maior entre os imigrantes da primeira geração. Segundo a pesquisa mencionada, apenas 44,5\% dos japoneses vivendo no Brasil sentiam-se ainda comprometidos com a sua religião tradicional. A mudança era mais dramática nos ambientes urbanos, onde já 50,3\% tinham se convertido ao Catolicismo. A porcentagem correspondente nas áreas rurais era de 36,5\%. Ainda mais crucial eram as diferenças entre as gerações. Em 1958, 70,6\% dos imigrantes nascidos no Japão declaram-se budistas, enquanto nas gerações seguintes, já nascidas no Brasil, o número era de 29,9\% na segunda geração e de 19\% na terceira (MAEYAMA, 1973, p.248).

\subsection{A terceira fase}

A terceira fase do Budismo no Brasil foi marcada por um interesse crescente de círculos intelectuais pelo Budismo Japonês, especialmente do Soto Zen, a partir da década de 1960. Em termos geográficos, esta dinâmica teve seu início na cidade de São Paulo. Logo depois, as mesmas tendências começaram a se articular em 
Brasília (PEREIRA, 2008, p.273). Três fatores principais foram constitutivos para este movimento. Primeiro, deve-se levar em consideração a repercussão de uma imagem positiva do Oriente, particularmente do Japão, já estabelecida pelas obras de filósofos, novelistas, poetas e historiadores que tinham se dedicado à contemplação sobre assuntos afins, devido a um entusiasmo pela Ásia, ao interesse romântico ou à curiosidade intelectual por esta parte do mundo, ainda relativamente desconhecida (COELHO, 1981). Desta maneira, os trabalhos de autores como Fagundes Varela (1841-1875), Machado do Assis (1839-1908), Raimundo Correia (1859-1911), Aluísio de Azevedo (1857-1913), Farias Brito (18621917), Alexandre Marcos Konder (1904 -1953) ou Lourival Nobre de Almeida (1906-1981), conforme mostra Albuquerque (2008, p.62-63), prepararam o terreno para um imaginário positivo do Oriente que, até mesmo, resistiu a ressentimentos do público brasileiro contra imigrantes "amarelos”, antes e depois da Segunda Guerra Mundial (LESSER, 1999b). Algo semelhante vale para a Cecília Benevides de Carvalho Meireles (1901-1964), professora de Literatura Oriental na Universidade do Distrito Federal (hoje Universidade do Estado do Rio de Janeiro). Em sua produção literária encontram-se obras de poesia que demonstram não apenas um bom conhecimento do Budismo, mas também uma simpatia por ele (OLIVEIRA, 2012), sensível desde a época em que a autora era aluna do ensino médio (CRISTÓVÃO, 1978).

O segundo fator era o crescente conhecimento sobre o Budismo em geral e o Budismo Zen em particular, devido a uma série de publicações, inclusive a versão portuguesa da famosa obra de Daisetz Teitaro Suzuki Introduction to Zen Buddhism (1934), lançada em 1961 pela editora Civilização Brasileira (ROCHA, 2008, pp.82-83). Paralelamente, os esforços de Suzuki em divulgar o zen por um público ocidental começaram a repercutir nas obras de alguns autores brasileiros, como Cícero Flores de Azevedo, conhecido sob seu pseudônimo Ciflovedo (1952), ou Antonio Xavier Teles (TELES, 1967). 
O mais importante foi o terceiro aspecto, isto é, o papel catalizador do já citado templo soto-zen Busshinji, na cidade de São Paulo, que durante o período em questão abriu-se gradativamente para uma clientela mais ampla. Uma das figuras-chave para este processo era o mestre Rosen Takashina Roshi, que tinha visitado a "colônia japonesa" pela primeira vez em 1955. Um ano mais tarde, sua ordem mandou-lhe novamente para o Brasil, desta vez por ocasião da fundação do templo Busshinji. Os atuais representantes do templo chamam atenção para o fato de que

com a chegada do Superior Ryohan Shingu, em 1956, os ensinamentos e a prática do Budismo Soto Zen começam a ser divulgados, atraindo não apenas seus antigos seguidores, que procuravam homenagear os antepassados, nos ofícios religiosos, como também outros, nem sempre descendentes, nas sessões de meditação zazen e nos retiros (COMUNIDADE, 2015).

Não existem informações oficiais sobre a composição do grupo de praticantes ocidentais, mas devido a diversas reportagens na mídia conhece-se pelo menos alguns nomes dos frequentadores brasileiros da época. A lista contém personalidades como o autor Nelson Coelho, a poeta Orides Fontela (1940-1998) (KUCK, 1969), a médica Maria das Dores Pereira da Silva (GONÇALVES, 2004a), a psiquiatra Nise da Silveira (GONÇALVES, 2002, p.178) e o professor universitário Eduardo Basto de Albuquerque (ALBUQUERQUE, 2002).

Provavelmente, os mais conhecidos representantes do primeiro círculo de praticantes do Zen foram Murilo Nunes de Azevedo e Ricardo Mário Gonçalves. Murilo Nunes de Azevedo compartilhou seu interesse profundo pelo Budismo com uma paixão pela teosofia. Algo semelhante vale para Ricardo Mário Gonçalves que, além do seu compromisso com o Budismo, foi associado à maçonaria. Ambos os personagens desempenharam um papel importante para a popularização do Budismo japonês no Brasil. Eles começaram suas "carreiras" budistas multifacetadas como praticantes do zen e acabaram se tornando líderes religiosos no âmbito do Budismo Shin. Azevedo, falecido em 2007, ocupava uma posição 
destacada no Templo Honpa Hongwanji em Brasília. Gonçalves é, até hoje, uma autoridade do templo Higashi Honganji, em São Paulo. Sob estas circunstâncias, seus trabalhos religiosos podem ser interpretados com sentido duplo: por um lado, agiram como mediadores espirituais no interior de comunidades budistas tradicionais, por outro lado, contribuíram para o desenvolvimento de um Budismo "abrasileirado".

\subsection{A quarta fase}

A quarta fase da história do Budismo no Brasil no sentido institucional tem sido marcada por uma crescente diversidade, no sentido de uma pluralização em termos de movimentos, grupos, centros e templos. Esta diversificação tem-se intensificado a partir dos anos 1980, no sentido de duas tendências. A primeira tendência tem a ver com o aumento do número de instituições budistas de cunho chinês e coreano. O Brasil recebeu a partir de 1949 ondas quantitativamente significantes de chineses. Conforme estimativas oficiais, até o fim dos anos de 1980 entraram cerca de 100.00o imigrantes da China no País. Algo semelhante vale para a imigração coreana, que se iniciou por volta de 1953 e se intensificou nos anos de 1960 e nas décadas seguintes (SHOJI, 2004). A primeira instituição budista chinesa, o templo Mo Ti na cidade de São Paulo, existe desde 1962 (YANG, 1995). Do ponto de vista cronológico, a inauguração de outros templos étnicos chineses, bem como a do único templo étnico coreano, se sobrepõem com eventos característicos para a terceira fase da história do Budismo brasileiro. A construção do segundo templo chinês, o Kuang Ying na cidade de São Paulo, começou 25 anos depois da abertura do templo Mo Ti. Em 1992, a ordem budista taiwanesa Fo Kuang Shan inaugurou o já mencionado templo Zu Lai em Cotia, seguido por três outros templos da mesma linha, a saber: no Rio de Janeiro (1996), em Recife (1999) e em Foz de Iguaçu (2000) (SHOJI, 2002). Em 1988, a única instituição do Budismo coreano tradicional, o Jin Kak da linha Chogye, foi inaugurado na cidade de São Paulo. 
A segunda tendência responsável pela diversificação do Budismo brasileiro está relacionada à ascensão numérica e à pluralização substancial do subcampo do “Budismo de conversão”. Como em outros países ocidentais, esta dinâmica ganhou força inicial tanto pela orientação espiritual da chamada contracultura, dos anos de 1960 e 1970 na espiritualidade asiática, quanto pela publicação acelerada de obras sobre religiões orientais, em muitos casos traduções de livros originalmente lançados em inglês (ROCHA, 2001, p.253-254). Até a década de 1980 a manifestação predileta do Budismo de conversão era o Budismo Zen. Alguns grupos de praticantes, compostos por brasileiros sem ascendência asiática, mantiveram seus vínculos com templos japoneses já existentes. A maior parte dos convertidos, porém, organizou-se em novas instituições independentes do ambiente étnico. Em casos em que os exercícios de convertidos foram realizados em templos tradicionais, os respectivos brasileiros e seus protagonistas nem sempre conviveram harmonicamente com a liderança e os integrantes da comunidade tradicional. Os exemplos mais citados a respeito referem-se ao já citado templo Busshinji, no bairro da Liberdade em São Paulo. Na história desta instituição foram registrados três casos problemáticos nesse sentido. O alvo da primeira polêmica foi Tokuda Ryotan, que logo depois da sua chegada, em 1968, foi criticado pela cúpula da instituição, que se mostrou incomodada por seu estilo nãoconvencional. Insatisfeito com a postura conservadora da maioria dos integrantes da instituição, Tokuda estabeleceu, em 1974, junto com um grupo de convertidos brasileiros, o centro de retiro Morro da Vargem em Ibiraçu (Espírito Santo). Mais tarde, Cristiano Bitti, que tinha feito parte do círculo de zazen em São Paulo, tornou-se um personagem importante para o Morro da Vargem, depois de ter passado alguns anos em um mosteiro Soto no Japão. De volta ao Brasil, assumiu a liderança do centro de retiro em Ibiraçu. Em 1984, Tokuda inaugurou um segundo centro de retiro chamado Pico dos Raios, em Ouro Preto, seguido pela abertura de outras instituições como em Brasília (1993) e no Rio de Janeiro (1994), como também do mosteiro Serra do Trovão, em Ouro Preto, dedicado ao treinamento de monges e de retiros extensos (ROCHA, 2001, p.255). 
Um destino semelhante sofreu Daigyo Moriyama Roshi, que assumiu a liderança espiritual do Busshinji, em 1993, depois de ter divulgado, desde os anos de 1960, o Budismo Zen para o público norte-americano da Califórnia. Sua abordagem "globalizante" ao Zen provocou tensões com os líderes locais da comunidade e finalmente a ruptura com a instituição. Desta separação resultaram dois centros “modernistas" próprios, ambos localizados em Porto Alegre. Dois anos mais tarde, as fricções crescentes entre ele e a hierarquia local levaram a sede japonesa a interferir, substituindo Moriyama pela brasileira Claudia Souza de Murayama, mais conhecida como Monja Coen, "título" que lembra seu treinamento monástico entre 1983 e 1995, em um templo do Soto-Zen em Nagoya, Japão. Na sua função, como líder do templo Busshinji, enfrentou uma situação ambígua. Em termos interinstitucionais ganhou reputação como presidente (1997-1998) da Federação das Seitas Budistas no Brasil e como membro do Conselho da Comunidade Budista Soto Zenshu da América do Sul. Do ponto de vista dos praticantes ocidentais, a monja desfrutou respeito como qualificada professora de dharma. Ao mesmo tempo, porém, ela não foi unanimemente aceita como líder da comunidade étnica. Mesmo assim, manteve-se na chefia da instituição até o fim do ano 2000, ou seja, até o momento em que o Reverendo Koichi Miyoshi, mandado ao Brasil pela sede japonesa do Soto Zen, tomou posse como novo líder espiritual do Busshinji. Consequentemente, a Monja Coen se desvinculou do templo Busshinji e fundou o Tenzui Zen Dojo como um centro zen, focado em budistas convertidos.

Paralelo a tendências inovadoras no setor do Budismo Zen, a Soka Gakkai, movimento neo-budista japonês, relacionado ao Budismo Nichiren começou a crescer. Nos anos 60, o grupo contava apenas com cerca de 150 membros, vinculados à “colônia japonesa”. No decorrer das décadas tornou-se, gradativamente, o ramo estatisticamente mais forte no campo do BudismoBrasileiro, que atualmente possui uma rede de centros geograficamente bem espalhada e uma oferta religiosa aceita por brasileiros sem ascendência asiática (PEREIRA, 2001, p.281-282). 
Mais recentemente, o Budismo de conversão tem-se manifestado em um número crescente de brasileiros atraídos pelo Budismo tibetano. A primeira instituição budista-tibetana em solo brasileiro foi inaugurada em 1988, na cidade de São Paulo, por seguidores de Tarthang Tulku, um mestre da linha Nyingma. Logo depois, discípulos de Lama Gangchen, representante da escola Guelug, fundaram o Centro de Dharma Shi De Choe Tsog, também localizado no bairro de Perdizes, em São Paulo. Em 1993, mais duas instituições foram abertas na cidade, a saber: o Centro Budista Mahabodhi (New Kadampa Tradition) e o Ödsal Ling (inspirado pelo mestre Nyingma, Chagdud Tulku). Em 1995, os discípulos de Chagdud Tulku inauguraram a sede do seu movimento, o templo Chagdud Gonpa Kadro Ling, em Três Coroas (Rio Grande do Sul). Nos anos seguintes a organização abriu uma série de centros locais em cidades como Belo Horizonte, Florianópolis, Rio de Janeiro e Salvador. Na mesma época, representantes da corrente Sakya fundaram um centro no Rio de Janeiro. Paralelamente, duas instituições associadas ao mestre Kalu Rinpoche da linha Kagyu abriram suas portas em Brasília e em Cotia. Finalmente, vale mencionar a inauguração do Centro Je Tsongkhapa, em Porto Alegre (2000), que faz parte da corrente tibetana Guelug. O fundador da instituição é Lama Segyu Rinpoche, um brasileiro que durante anos operou como médium da Umbanda, até se converter ao Budismo tibetano, no qual fez "carreira" particularmente a partir do momento em que foi oficialmente reconhecido como a reencarnação de um mestre tântrico do século XVI. Entre 1994 e 2002, Segyu Rinpoche foi diretor da Healing Buddha Foundation, em Sebastopol, Califórnia. (SIMÕES, 2000). Devido às experiências adquiridas por meio do trabalho constante com o público norte-americano, Segyu Rinpoche substituiu a Healing Buddha Foundation pelo centro de meditação Juniper atualmente apresentado como "uma escola de meditação em que a sabedoria e a experiência de uma longa tradição [...] são oferecidas em uma forma secularizada adaptada à cultura [...] moderna" (JUNIPER, 2016). 


\section{Avaliação do atual Budismo de imigração de origem japonesa}

Os parágrafos anteriores deixaram claro que o Budismo brasileiro contemporâneo deve ser entendido como um conglomerado de fenômenos associados. Entre os últimos, o Budismo de imigração - que durante muitas décadas podia reivindicar ser a única ou, pelo menos, a mais acentuada manifestação do Budismo em uma sociedade maioritariamente católica representa não apenas uma faceta especifica do Budismo, mas também uma linha estatisticamente minoritária, em comparação com grupos e centros cujos membros são convertidos a esta religião. A situação fica ainda menos confortável pelo fato de que, devido a popularização do Budismo, uma série de suas práticas e ensinamentos estão acessíveis para um público maior, sem que esta disponibilidade requeresse uma adesão definitiva a uma escola budista (USARSKI, 2012). Tudo isso tem contribuído para a consciência dos representantes dos templos tradicionais de que o Budismo de imigração está passando por uma crise profunda. Já em 2004, um ministro líder da escola Jodo-shin-shu de São Paulo, expressou-se de maneira cética dizendo:

\footnotetext{
Na prática, é fácil perceber que os descendentes de japoneses pouco se interessam pelos templos budistas [...]. Assim, não será um exagero dizer que quando o último imigrante falecer, só resta aos missionários budistas fecharem os templos e regressarem ao Japão, sendo interessante recomendar ainda ao último a partir que desligue a luz antes de seguir para o aeroporto. (GONÇALVES, 2004b)
}

Esta crise tem se intensificado durante um longo tempo e se reflete nos resultados dos censos nacionais, desde 1950. Abstraindo-se de problemas epistemológicos discutidos em outras publicações (USARSKI, 2008), um indicador para a evolução numérica do subcampo do "Budismo étnico japonês" encontra-se nas correlações entre as rubricas "raça" e "religião" nos questionários do IBGE, que permitem a construção do parâmetro estatístico "Budismo amarelo". Comparando os respectivos valores dos censos da segunda metade do século XX e dos anos 2000 e 2010, percebe-se uma diminuição numérica contínua deste tipo de budistas, 
apesar de um crescimento constante da população brasileira em geral. Segundo o IBGE, em 1950, 152.572 brasileiros de cor de pele amarela autodeclaram-se budistas. Trinta anos mais tarde, o valor tinha caído para 119.802. O censo de 2000 contou 81.345 budistas desta categoria. Em 2010, apenas 76.896 brasileiros identificaram-se como budistas de “cor amarela”. Esta tendência se reflete também na decrescente porcentagem de budistas de "cor de pele amarela" da população brasileira. Em 1991, o respectivo valor era 0,06\%. O último caiu para 0,05\% em 2000 e para 0,04\% em 2010.

Esta dinâmica negativa se explica por uma série de razões, dentre elas por motivos demográficos, institucionais e "mercadológicos". A razão demográfica mais significante constata a dificuldade das famílias de descendência japonesa em manter o Budismo tradicional no seu interior. Durante as primeiras décadas, os imigrantes japoneses se preocupavam fortemente com a coesão das suas famílias e consideravam a manutenção do seu "capital cultural", trazido para o Brasil, como o principal meio para este fim. Uma das manifestações desta preocupação foi o fato de que em muitas famílias o Budismo foi praticado como a religião domiciliar herdada dos antepassados (MAEYAMA, 1983, p.206). Estes hábitos foram desafiados pelo processo de aculturação das gerações posteriores e sua ascensão social. Esta dinâmica exigia a ampliação do horizonte de contatos para além do enclave étnico e a flexibilização dos padrões de comunicação, em desfavor da predominância da língua japonesa. Ambos os fatores tinham um impacto significativo sobre a religiosidade dos indivíduos em questão. Um dos efeitos colaterais do envolvimento em redes sociais, fora do ambiente étnico, era o crescimento de casamentos interétnicos, visto pela geração mais velha como uma ameaça ao sistema familiar tradicional (CARVALHO, 2003, p.41). Até os anos 40, menos de $2 \%$ dos membros da comunidade nascidos no Japão e menos de 6\% dos nikkeis estavam casados com um cônjuge que não pertencia à colônia japonesa (LESSER, 1999c, p.104). No final dos anos 50 e no início dos 60 a taxa de casamentos fora do grupo era de 18,36\% para os homens e 7,63\% para as mulheres descendentes de japoneses. Em 1988, apenas cerca a metade de nipo-brasileiros 
estavam casados com um cônjuge de descendência japonesa (CARVALHO, 2003, p.43). Estas tendências resultaram em um crescente número de famílias cuja coesão requer o respeito mútuo pelas convicções e valores do cônjuge. Trata-se de espaços sociais em que assuntos ideológicos, antigamente auto-evidentes, tornaram-se objetos de "negociação". Os últimos atingem também a questão da educação religiosa adequada dos filhos. Em casos em que um cônjuge não é budista, o Budismo não mais se apresenta como a referência "natural" para a socialização infantil.

Quanto à citada relativização da língua japonesa como meio de comunicação principal vale lembrar o seguinte: pesquisas do IGBE, realizadas em 1940 (USARSKI, 2008, p.145), em diferentes colônias japonesas no Brasil, confirmaram uma correlação positiva entre a manutenção do japonês e a manutenção do Budismo como religião familiar. Na colônia de Tupã, por exemplo, cerca de $98 \%$ ainda preferiam a língua japonesa como a principal forma de comunicação. E $21 \%$ das pessoas abaixo de 20 anos e 17\% das pessoas acima de 20 anos não mais se identificavam com nenhuma das religiões japonesas, inclusive o Budismo. A mais alta porcentagem de indivíduos $(54,8 \%<20$ anos e 54,8\% $\geq 20$ anos) que haviam abandonado as religiões japonesas foi encontrada em Presidente Prudente onde mais de $16 \%$ dos integrantes das famílias de imigrantes não falava mais japonês em casa.

O declínio numérico do Budismo de imigração se reflete mais evidentemente nas estatísticas do IBGE que indicam um "envelhecimento" deste ramo do Budismo brasileiro. Em 2000, apesar do aumento de cerca de 15\% na população do Brasil, ao longo da década anterior, 45,13\% dos budistas de "cor amarela” tinham mais de 60 anos e só 12,19\% tinham menos de 20 anos. O significado dessas proporções fica claro quando comparamos esses valores com os dados fornecidos pelo IBGE em 1950, indicando uma relação inversa naquela época, quando a maioria $(51,52 \%)$ dos budistas de "cor amarela" tinha menos de 20 anos de idade, enquanto menos de $5 \%$ tinha mais de 60 anos. O impacto desta tendência sobre o Budismo étnico é 
ainda intensificado pela falta de novos imigrantes, que poderiam revitalizar a vida das comunidades budistas japonesas no Brasil. Em vez disso, observa-se nas últimas décadas uma dinâmica inversa, conhecida como movimento dekassegui. Esse retorno de nipo-brasileiros para o Japão é particularmente atraente para indivíduos relativamente jovens, conscientes da sua força física e cheios de esperança para um futuro duradouro. Para ter uma ideia geral do peso estatístico desta dinâmica, basta lembrar que até à crise econômica mundial, em 2009, mais de 300.ooo brasileiros viviam no Japão (IZUMI, 2012, p.130).

A tendência de envelhecimento dos grupos budistas japoneses tradicionais repercute também na maneira como os templos são administrados. Isso vale, por exemplo, para as instituições da corrente Honpa Hongwanji. Kyoya Imai, ministro japonês desse ramo religioso, afirma que os líderes das comunidades no Brasil "não abrem a mão para brasileiros, nem conseguem transmitir mais para os jovens nikkeis. Somente os japoneses ou nisseis que falam a língua japonesa estão nos templos." 1 No caso da corrente citada, a falta de disponibilidade por parte dos responsáveis em delegar tarefas administrativas, em prol de ampliação do número de membros ativos, teve consequências sérias, prejudicando a rotina religiosa de várias comunidades locais, cujas instituições são privadas de uma autoridade religiosa residente. Somente a sede central na cidade de São Paulo está bem equipada com um staff religioso, enquanto, por exemplo, mais de vinte comunidades no interior do estado e três no Paraná não desfrutam da presença permanente de um reverendo local e dependem das visitas de uma autoridade religiosa de outra cidade.

Uma das consequências desta situação repercute no seguinte depoimento de um "buscador espiritual” em forma de uma mensagem em 10 de janeiro de 2012 para a e-lista Budismo_Shin@yahoogrupos.com.br. O respectivo e-mail diz:

\footnotetext{
${ }^{1}$ Citação retirada de uma mensagem de Kyoya Imai enviada por e-mail para o autor do artigo, em 11 de setembro de 2007.
} 
Moro em Campo Grande (MS), e até a semana passada achava que por aqui não havia qualquer templo Shin, entretanto [...] descobri a existência de um. Passei em frente ao templo, que se encontrava fechado, e acabei descobrindo, perguntando ao dono de um quiosque nos arredores, que as cerimônias acontecem sempre no dia 8 de cada mês, na parte da tarde, independente do dia da semana em que cair. Confesso que achei estranho, pois em 70\% das vezes as cerimônias acontecem em dias úteis, o que, pensei eu, deve reduzir o público das mesmas. [...] Como não havia qualquer telefone de contato no site, fui ao templo por volta do meio-dia e lá encontrei-me com os reverendos Nakashima e Ueno, que me disseram que a cerimônia começaria às 14:0o. Voltei para casa para almoçar, peguei minha esposa e fomos à cerimônia, realizada totalmente em japonês, exceção feita a uma rápida tradução feita pelo rev. de seu sermão. Ao final, confraternizamo-nos com os irmãos e conversamos um pouco com os reverendos, muito amáveis, diga-se de passagem. Por relevante, quero destacar que, salvo engano, apenas eu e minha esposa éramos nãodescendentes de japoneses, que, em sua maioria, eram idosos acima de 70 anos, o que me chamou muito a atenção. O público total deve ter ficado em torno de 25 pessoas, que achei pequeno em relação ao tamanho da cidade.

Quanto aos aspectos "mercadológicos" responsáveis pela crise do Budismo de imigração de origem japonesa, observa-se a falta de providências sistemáticas em prol de superação dos limites de uma religião étnica e da transformação dos templos "fechados" em comunidades abertas para o público geral. No mínimo seriam necessários esforços para o aperfeiçoamento dos meios de comunicação, com potenciais interessados em uma oferta religiosa "estranha", tanto no sentido dos seus conteúdos quanto devido ao desconhecimento da língua japonesa, ainda preferida pelos líderes e membros de muitas comunidades budistas tradicionais. Trata-se de uma consequência a longo prazo das circunstâncias históricas sob as quais o Budismo de imigração foi introduzido no Brasil, numa época em que os imigrantes japoneses ainda estavam convencidos de que a sua moradia no país anfitrião seria temporária. Em reação a este problema, a maioria dos responsáveis pelos templos reconhecem as dificuldades, porém, sem necessariamente perder a esperança por um futuro mais positivo. Entre os sinais auspiciosos devem ser lembrados o investimento de alguns templos no trabalho religioso direcionado a jovens descendentes, os esforços pontuais de tradução do material religioso para o português e a organização de cursos locais sobre o Budismo para o público paulistano. Apesar destas medidas, porém, do ponto de vista da sociologia da 
religião e face aos dados resumidos no decorrer deste artigo, não há indicações para uma inversão da situação precária do Budismo de imigração no Brasil.

\section{Comentário final}

O balanço sobre o fenômeno enfocado neste artigo seria desequilibrado se ele se contentasse com a identificação de tendências e problemas, no sentido da manutenção do Budismo étnico como tradição familiar, suas manifestações sociológicas e sua função como constituinte da identidade transmitida através de gerações historicamente vinculadas a fluxos migratórios do Japão para o Brasil. Há outro lado da presença do Budismo étnico no País que não deve ser esquecido e com o qual se fecha este artigo.

Vale, particularmente, lembrar dois aspectos afins. O primeiro já foi mencionado de passagem e deve ser repetido aqui devido a sua importância: a função catalizadora de alguns templos japoneses tradicionais para a formação de um Budismo de conversão. Embora ele tenha absorvido, ao longo do tempo, uma série de influências, foi decisivo para sua formação o impulso inicial recebido por instituições e autoridades enraizadas no ambiente étnico japonês. Em alguns casos, particularmente vinculados ao Budismo zen, este impulso inicial se desdobrou nos budistas brasileiros sem descendência japonesa, cuja carreira religiosa começou em um templo tradicional e que posteriormente se dedicou a divulgar o Budismo para além da comunidade étnica. O segundo aspecto tem a ver com o fato de que o sucesso do Budismo na Ásia não se reduz ao estabelecimento de uma religião institucionalizada. Mais importante foi o potencial civilizatório que fez com que o Budismo moldasse as culturas dos povos convertidos a esta religião. No caso do Japão, a atmosfera espiritual que irradiava do Budismo zen “animou” todas as esferas de vida (SUZUKI, 1959): "Nesse sentido, o Zen está intimamente associado às artes, à pintura, à cerimônia do chá, ao arranjo das flores, à esgrima e à arte dos arqueiros, entre outras" (SUZUKI, 1979, p. 5), inclusive artes marciais como a do 
karate-dō (BARREIRA; MASSIMI, 2003) e do aikidō (GREENHALG, 2003), a caligrafia japonesa (shodō) (MIYASHIRO; LARA; GOUVEIA, 2013) ou as poesias haicai (VIEIRA, p. 1989). A atração por estas "técnicas culturais" no Brasil não se explica meramente por sua introdução por imigrantes japoneses, mas não se pode negar a relevância da comunidade étnica para este processo.

Atualmente, há no Brasil mais que 300 aikidō-dojos (academias), conforme a Aikido Brasil (2016). Em muitos deles atuam professores nascidos em famílias de imigrantes, enfatizando as raízes budistas da sua arte marcial e enriquecendo os treinos com referências à espiritualidade zen. Exposições da Caligrafia Japonesa, por exemplo, no Museu de Arte de São Paulo (2008), ou na sede paulistana da Sociedade Brasileira de Cultura Japonesa (2014), garantem um acesso do grande público a esta técnica e a seus produtos, mesmo que o "espectador leigo" não esteja suficientemente familiarizado com a "leitura entre as linhas" que sensibiliza para o espirito subjacente das obras expostas. O haicai é considerado como a expressão estética originalmente japonesa que sofreu a maior transformação cultural no Brasil. (FRANCHETTI, 1994). Mesmo assim, não se deve esquecer que esta arte foi inicialmente praticada por integrantes da colônia japonesa e que alguns dos seus representantes desenvolveram "um importante trabalho de difusão e adaptação do haicai à natureza brasileira.” (FRANCHETTI, 2008, p.266).

Tudo isso aponta para fenômenos cujas inter-relações com o Budismo étnico japonês ainda não foram suficientemente analisadas. Será uma futura tarefa para pesquisadores do Budismo no Brasil estudar mais profundamente o impacto "tácito" do legado espiritual deixado pelos imigrantes japoneses no seu país anfitrião. 


\section{REFERÊNCIAS}

AGUIAR, José Otávio. Literatura Wushia, Budismo, marcialidade e ascese: da arte da guerra à historiografia sobre o mosteiro de Shaolin'. Antíteses, Londrina, v. 2, n. 4, p.599619, 2009.

AIKIDO BRASIL. Academias e Dojos de Aikido no Brasil. Disponível em: <http://www.aikidobr.com.br/dojos/>. Acesso em: 15 abr. 2016.

ALBUQUERQUE, Eduardo Basto de. Intellectuals and Japanese Buddhism in Brazil. Japanese Journal of Religious Studies. Tokyo, v. 35, n. 1, p.61-79, 2008.

ALBUQUERQUE, Eduardo Basto de. Um mestre zen na terra da garoa. In: USARSKI, Frank (org.): O Budismo no Brasil. São Paulo: Lorosae, 2002. p.151-170.

BARREIRA, Cristiano Roque Antunes; MASSIMI, Marina. As Idéias Psicopedagógicas e a Espiritualidade no Karate-Do segundo a obra de Gichin Funakoshi. Psicologia:

Reflexão e Crítica, Porto Alegre, v. 16, n. 2, p.379-388, 2003.

BRASIL. Instituto Brasileiro de Geografia e Estatística - IBGE - Brasil 500 anos.

Estatísticas de povoamento. Imigração por nacionalidade. 2013. Disponível em:

<http://brasil5ooanos.ibge.gov.br/estatisticas-do-povoamento/imigracao-pornacionalidade-1884-1933.html>. Acesso em: 29 de janeiro de 2013.

BUSSCHE, Eric Vanden. A Dimensão Histórica das Relações Sino-Brasileiras (Séc.: XVI1943). Revista Tempo Brasileiro, Rio de Janeiro, v. 137, p.85-98, 1999.

CARVALHO, Daniela de. Migrants and Identity in Japan and Brazil: The Nikkijin. London and New York: Routledge, 2003.

CIFLOVEDO. Ilusão, Desejo e Nirvana. São Paulo: Editora Leia, 1952.

COELHO, Jacinto do Prado. Dicionário das literaturas portuguesa, brasileira e galega. v. 3. Porto: Figueirinhas, 1981. [Verbete: Orientalismo na literatura brasileira, p. 770-772].

COMO FOI FUNDADA A HBS NO BRASIL. Revista Lótus, São Paulo, n. 19, p.6, 2001.

COMUNIDADE BUDISTA SOTO ZENSHU DA AMÉRICA DO SUL. História. Disponível em: <http://www.sotozen.org.br/templo.php>. Acesso em: 26 de março de 2015.

CRISTÓVÃO, F. 'Cartas Inéditas de Cecília Meireles a Maria Valupi’. Colóquio Letras, Lisboa, n. 46, nov., p.20-27, 1978.

ELIAS, Maria José. Introdução ao Estudo da Imigração Chinesa. Anais do Museu Paulista, São Paulo, v. XXIV, p.55-100, 1970. 
FRANCHETTI, Paulo. Notas sobre a história do haikai no Brasil. Revista de Letras, Taguatinga, v.34, n.1, p.197-213, 1994.

FRANCHETTI, Paulo. O Haicai no Brasil. Alea: Estudos Neolatinos, Rio de Janeiro, v.10, n.2, p.256-269, 2008.

GONÇALVES, Mario Ricardo. As flores do dharma desabrocham sob o Cruzeiro do Sul: aspectos dos vários "budismos" no Brasil. Revista USP, São Paulo, n. 67, p.198-207, 2005 .

GONCALVES, Mario Ricardo. Homenagem aos Imigrantes Japoneses Pioneiros do Budismo no Brasil, 2004a. Disponível em:

<http://www.dharmanet.com.br/honganji/vesak2004.htm> Acesso em: 14 de novembro de 2010.

GONCALVES, Mario Ricardo. O futuro dos templos budistas no Brasil - Conferência Pública realizada em Araçatuba em 23 maio 2004, durante as celebrações do Cinquentenário do Templo Araçatuva Nambei Honganji, 2004b. Disponível em: <http://www.honganji.org.br/futuro.htm>. Acesso em: 30 março 2015.

GONÇALVES, R.M.. A trajetória de um budista brasileiro. In: USARSKI, Frank (Org.): $\mathbf{O}$ Budismo no Brasil. São Paulo: Lorosae, 2002. p.171-192.

GREENHALGH, Margaret. Aikidō and spirituality: Japanese religious influences in a martial art. Saarbrücken: VDM, Verlag Dr.Müller, 2003.

HANDA, Tomoo. O Imigrante Japonês. História de sua vida no Brasil, São Paulo: T.A. Queiroz; Centro de Estudos Nipo-Brasileiros, 1987.

IZUMI, Patrícia Tamiko. Envelhecimento dos imigrantes japoneses em São Paulo, Brasil. Revista Migrações - Número Temático Imigração e Envelhecimento Ativo, Lisboa, n. 10, 127-141, 2012.

JUNIPER . Juniper Story. The quest for depth without dogma. Disponível em: <https://www.juniperpath.org/story/>. Acesso em: o9 fev. 2016.

KUCK, Cláudio. Os budistas procuram a paz. O Cruzeiro, Rio de Janeiro, 15 maio 1969.

LEITE, José Roberto Teixeira. A China no Brasil. Campinas: Editora da Unicamp, 1999.

LESSER, Jeffrey. Immigrants, Minorities, and Struggle for Ethnicity in Brazil. Durham \& London: Duke University Press, 1999c.

LESSER, Jeffrey. Negotiating National Identity: Immigrants, Minorities, and the Struggle for Ethnicity in Brazil. Durham \& London: Duke Press, 1999a.

LESSER, Jeffrey. Tornando-se japonês: literatura de viagem em busca de identidade nacional. Estudos Ibero-Americano, Porto Alegre, v. XXV, n.2, p.175-184, 1999b. 
MAEYAMA, Takashi. Japanese Religions in Southern Brazil. Latin American Studies, Austin, v. 6, p.181-238, 1983.

MAEYAMA, Takashi. Religião, parentesco e as classes médias dos japoneses no Brasil urbano. In: SAITO, Hiroshi; MAEYAMA: Assimilação e Integração dos Japoneses no Brasil. Petrópolis: Vozes, 1973. p.240-272.

MITA, Chiyoko. Bastos: uma comunidade étnica japonesa no Brasil. São Paulo: Humanitas, FFLCH/USP, 1999.

MIYASHIRO, Rafael Tadashi; LARA, Arthur Hunold.; GOUVEIA, Anna Paula Silva Percursos em definição: A caligrafia japonesa no Brasil, in: NAGAE, Neide Hissae; SHIODA, Cecília Kimi Jo; YOSHIURA, Eunice Vaz (Org.). Dô - Caminho da arte: do belo do Japão ao Brasil. São Paulo: Editora da UNESP, 2013. p.131-151.

NAKAMAKI, Hirochika. Japanese Religions at Home and Abroad. Anthropological Perspectives. London \& New York: Routledge Curzon, 2013.

OLIVEIRA, G.P. 'Cecília Meireles e a Índia: das Provisórias Arquiteturas ao "Êxtase Longo De Ilusão Nenhuma”'. Religare, João Pessoa, v. 9, n. 2, p.153-161, 2012.

PADGETT, Douglas M. “Americans Need Something to Sit On”, or Zen Meditation Materials and Buddhist Diversity in North America'. Journal of Global Buddhism, Pennsylvania, v. 1, p. 61-81, 2000.

PEREIRA, Ronan Alves. Instituições Ético-Religiosas Japonesas no Distrito Federal. In: SHIGERU, Hayashi (Org.). Centenário da imigração japonesa no Brasil e cinquentenário da presença Nikkey em Brasília. Brasília: FEANBRA, 2008. p.274278.

PEREIRA, Ronan Alves. O Budismo Leigo da Soka Gakkai no Brasil: da revolução humana à utopia mundial. 2001. Tese (Doutorado em Antropologia) - Instituto de Filosofia e Ciências Humanas, Universidade Estadual de Campinas, Campinas, Brasil.

PROHL, Inken.; RAKOW, Katja. Transformationen buddhistisch inspirierter Vorstellungen und Praktiken: Eine empirische Studie im Raum Berlin. Transformierte Buddhisten, Alemanha, n. 1, p.3-27, 2008.

ROCHA, Cristina Moreira da. All roads come from Zen. Japanese Journal of Religious Studies, Tokyo, v. 35, n.1, p.81-94, 2008.

ROCHA, Cristina Moreira da. Catholicism and Zen Buddhism: A Vision of the Religious Field in Brazil. In: CUSACK, Carol M.; OLDMEADOW, Peter (eds.): The End of Religions? Religion in an Age of Globalization. Sydney: The University of Sydney, 2001. p.249-265.

ROCHA, Cristina Moreira da. Zen in Brazil: The Quest for Cosmopolitan Modernity. Honululu: University of Hawai'i Press, 2006. 